\title{
Combined spinal and video-assisted thoracoscopic (VATS) approach to thoracic neurogenic dumbbell tumour in the prone position: a case report
}

\author{
Thirugnanam Agasthian, James Chee Min Khoo
}

Mt Elizabeth Medical Centre, Singapore

Correspondence to: Thirugnanam Agasthian, MBBS, MMed (Surgery), FRCS (Ed), FRCS (G). Mt Elizabeth Medical Center, Singapore.

Email: t.agasthian@gmail.com.

\begin{abstract}
Neurogenic tumours are the third commonest cause of all mediastinal tumours with $10 \%$ of them having intraspinal extension with variable spinal and mediastinal components. This is often referred to as a dumbbell neurogenic tumour. In such cases the surgical team comprises a neurosurgeon and a thoracic surgeon. Though several surgical approaches have been described for dumbbell tumours of the thoracic region, the optimal surgical approach is a single stage posterior laminectomy combined with video-assisted thoracoscopic (VATS). In this approach the posterior spinal approach is done in the prone position by the neurosurgeon. This is then followed by repositioning to a lateral decubitus position for excision by VATS by the thoracic surgeon. We describe a case of a 63-year-old male presenting with mild weakness of the lower limbs and right sciatica. Magnetic resonance imaging (MRI) whole spine showed with an $8.4 \mathrm{~cm} \times 4.5 \mathrm{~cm} \times 3.7 \mathrm{~cm}$ dumbbell thoracic schwannoma arising from the T10 thoracic root. This was excised first by a single stage combined posterior laminectomy by the neurosurgeon followed by the VATS approach, both being performed in the prone position. Postoperative course was complicated by right femoral nerve neuropraxia from compression nerve injury to the groin. He made a almost complete recovery from the neuropraxia on subsequent follow-up.
\end{abstract}

Keywords: Case report; video-assisted thoracoscopic (VATS); prone; schwannoma

Received: 25 June 2020; Accepted: 28 December 2020; Published: 20 January 2023.

doi: 10.21037 /jovs-20-141

View this article at: http://dx.doi.org/10.21037/jovs-20-141

\section{Introduction}

Neurogenic tumours are the third commonest cause of all mediastinal tumours with $10 \%$ having intraspinal extension with variable mediastinal and spinal components $(1,2)$. The surgical team usually involves a thoracic and a neurosurgeon if there is an intraspinal extension. The surgical technique is either a single stage posterior only approach or a Single stage combined posterior approach with video-assisted thoracoscopic (VATS) depending on the tumour size, invasiveness and extend of intraspinal and mediastinal components (3). In the combined approach the posterior spinal part is done first followed by VATS and involves repositioning the patient from prone to lateral decubitus position which prolongs surgical time, re-draping and increases costs (4). We describe a case of a thoracic neurogenic dumbbell tumour excised by a single stage combined posterior and VATS approach in the prone position.

We present the following article in accordance with the CARE reporting checklist (available at https://jovs. amegroups.com/article/view/10.21037/jovs-20-141/rc).

\section{Case presentation}

Patient is a 63-year-old male presenting with mild weakness of the lower limbs and right sciatica. He has a past history of hypertension, treated syphilis, obesity [body mass index (BMI) 35], smoking and hyperlipidaemia. Magnetic resonance imaging (MRI) of the whole spine revealed a right $8.4 \mathrm{~cm} \times 4.5 \mathrm{~cm} \times 3.7 \mathrm{~cm}$ dumbbell neurogenic tumour arising from T10-T11 neural foramina with associated widening of adjacent neural foramina and extension into the 


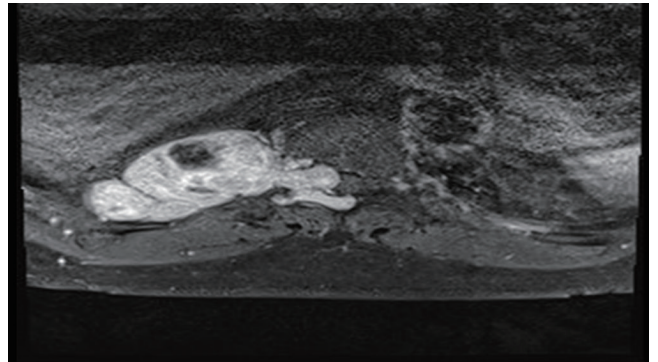

Figure 1 Preoperative axial T1 weighted post contrast T10 dumbbell neurogenic tumour.

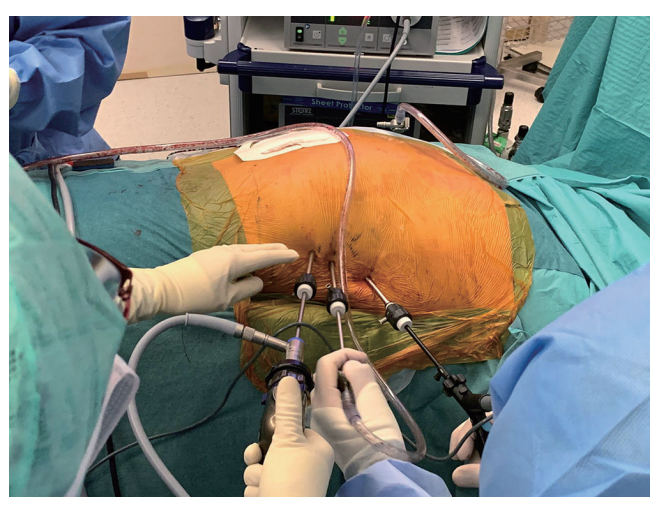

Figure 2 Operative view of right video assisted thoracoscopic surgery in prone position.

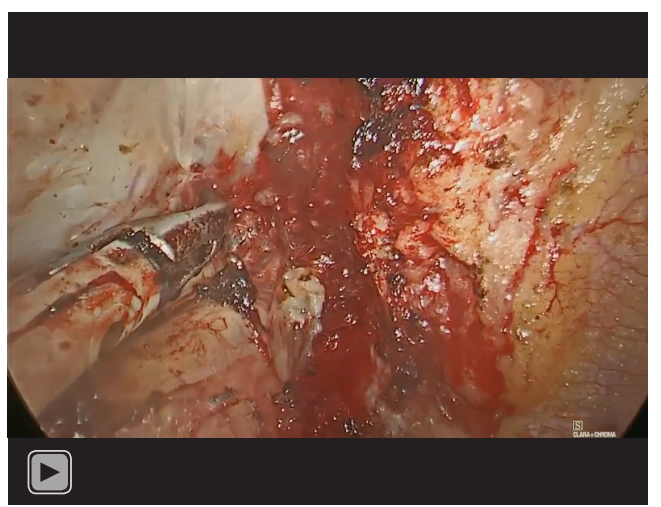

Video 1 Right video assisted thoracoscopic surgery excision of neurogenic tumour in prone position.

spinal canal with displacement of the thoracic spinal cord to the left. There were also associated degenerative changes throughout the spine with multilevel disc desiccation and protrusions facet joint arthrosis and hypertrophy of ligamentum flavum, and borderline anterolisthesis with multilevel mild spinal canal foraminal stenosis causing his right sciatic (Figure 1).

He underwent resection through a combine single stage posterior and VATS approach. After general anaesthesia, a left sided double lumen endotracheal tube was placed. He was positioned in a prone position with extra care and padding taken to protect vital compression points.

Posterior midline laminectomy was first performed by the neurosurgeon for the extramedullary, intra and extradural component of the neurilemmoma. Intraoperatively the lesion was noted to originate extramedullary from the right T10 root. It extended through the dura into the enlarged intervertebral foramen with the major extradural component eroding the pedicle and facet joint and extending anteriorly to the retro pleural space and the posterior mediastinum. The firm tumour was excised piecemeal with the dumbbell origin divided from its origin from the T10 intraspinal nerve root. The affected bony edges were resected, and the main component was dissected free from its surrounding attachments and delivered into the retro pleural space, sparing the intercostal vessels. The dura and the wound were then closed after meticulous hemostasis.

This was followed by VATS also in the prone position. The right lung was isolated. One $5-\mathrm{mm}$ camera port was placed directly over the T10 level at midaxillary line. Two $5 \mathrm{~mm}$ working port incisions were made at $\mathrm{T} 8$ and $\mathrm{T} 12$ levels respectively in the posterior axillary line. A 5-mm 30 degrees camera was used (Figure 2). The previously divided intraspinal and mediastinal component of the neurogenic tumour was identified and was noted to bilobed with cystic components. Associated scalloping of the adjacent rib by the tumour was noted. The overlying mediastinal pleura was first incised. En bloc removal of the tumour was done with division of distal T10 nerve root and other smaller nerve tributary extensions from adjacent intercostal and sympathetic nerves. Care was taken not to injure the adjacent intercostal vessels. The tumour was removed via an endobag by enlarging one of the 5 -mm incision and a F20 chest tube was inserted through the same incision. Intraoperative blood loss was minimal and operative time for VATS was 115 minutes (Video 1). Post operatively he had femoral nerve neuropraxia probably due to the prone position exacerbated by his high BMI. Chest tube was removed on $3^{\text {rd }}$ postoperative day (POD). Due to limb physiotherapy and rehabilitation for his femoral nerve neuropraxia he was discharged on $14^{\text {th }}$ POD. Final histology was a $9.5 \mathrm{~cm} \times 4.5 \mathrm{~cm} \times 2.5 \mathrm{~cm}$ benign schwannoma (Figure 3). The post-operative MRI scan showed no residual tumour. 


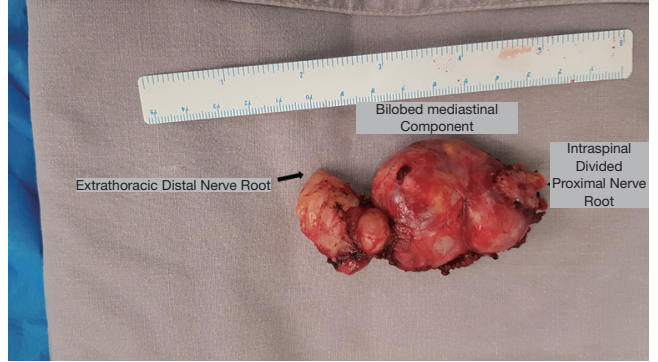

Figure 3 Schwannoma.

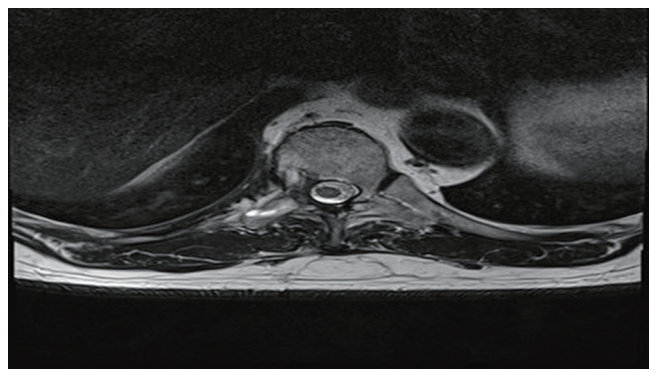

Figure 4 Postoperative axial T2 weighted MRI scan showing no residual disease. MRI, magnetic resonance imaging.

(Figure 4). At follow-up in clinic he had near complete resolution of his femoral nerve neuropraxia.

All procedures performed in this study were in accordance with the ethical standards of the institutional and/or national research committee(s) and with the Helsinki Declaration (as revised in 2013). Written informed consent was obtained from the patient for publication of this case report and accompanying images and videos. A copy of the written consent is available for review by the editorial office of this journal.

\section{Discussion}

Neurogenic tumours are the third commonest cause of mediastinal tumours with about $75 \%$ occurring in the posterior mediastinum due to the presence of multiple neural plexuses. About $10 \%$ have intraspinal extension with varying mediastinal and spinal components. $U p$ to $40 \%$ of intraspinal dumbbell tumours are asymptomatic even with radiological displacement of spinal cord. Therefore preoperative MRI of the spine is mandatory in all paravertebral neurogenic tumours to rule out intraspinal extension and to plan appropriate surgical approach. Spinal schwannomas account for $25 \%$ of all spinal tumours and commonly occurs in the thoracic region. It can occur solely in the spinal canal or extend along the nerve root to the extra vertebral space through the intervertebral foramen and become dumbbell or hour glass shaped tumour. They can be classified into 4 sub types depending on the degree of spinal and mediastinal extensions. The intraspinal extension can be intra or extramedullary, intra or extradural or foraminal. The mediastinal part is usually well encapsulated and can be bilobed with cystic components. It can vary from small to large and rarely invasive in malignant cases. Up to $10 \%$ of dumbbell tumours are malignant $(1,2)$.

Historically several approaches have been described for dumbbell tumours in the thoracic region. The surgical approaches are either a single stage posterior only approach, single stage anterior approach or a Single stage combined posterior approach with VATS or thoracotomy (3-7). Optimal approach will depend on tumour size, invasiveness and extend of intraspinal and mediastinal components (5). In cases where the mediastinal extension is only foraminal or a small mediastinal component it can be removed in a single stage posterior approach by laminectomy alone by an experienced neurosurgeon. Most times a combined approach involving both a neurosurgical and thoracic team is needed (3-7).

Single stage posterior approach is effective for resecting tumours with a predominantly intraspinal component. It involves laminectomy. Exposure can be enhanced by additional facetectomy, pediculectomy costotransversectomy or rib resection depending on the size and invasiveness of the mediastinal component. Advantages of this approach are single incision with less muscle damage, blood loss, operative time and postoperative pain (7). Main disadvantages are need for spinal instrumentation due to spinal instability from the extended bony resections and possible injuries to intrathoracic structures due to limited exposure. It is also generally contraindicated in malignant cases due to possible adequacy of surgical margins (7).

Combined posterior laminectomy and VATS is the procedure of choice for most dumbbell tumours with large mediastinal component. It allows for less posterior bone removal and the need for complex expensive spinal instrumentation to reduce spinal instability (3). Though some advocate doing the thoracic part first followed by spinal in combined cases, a posterior approach should always be performed first to decompress the spinal cord and release the tumour from the intraspinal nerve root. This reduces risk of spinal cord injury during subsequent mediastinal component removal $(3,6)$. Since the advent of VATS, thoracotomy is rarely used except in large invasive malignant tumours 
where an anterior only approach is preferred. Advantages of VATS are it causes less pain, pulmonary dysfunction, chestwall trauma and immune derangement. It provides excellent exposure of the whole chest for safe dissection under direct visualization. Its disadvantages are extra incisions and need for repositioning (4) This can be avoided as shown in our case by doing both combined procedures in the prone position as it saves operative time and cost.

Prone position in thoracic surgery was popular in the early $20^{\text {th }}$ century for airway management in patients undergoing lung surgery for bronchiectasis and lung abscess. It helped to prevent the spillage of purulent material into healthy parts of the lung during pulmonary resections, but became obsolete with the advent of doublelumen endotracheal tubes. It was revived again in the 1990's for mobilization of the thoracic oesophagus by VATS for esophageal cancers. In the prone position the lung naturally falls away from the posterior mediastinum under gravity giving excellent exposure to the posterior mediastinum. It also minimises lung trauma by abolishing the need for excessive lung retraction by an additional surgical assistant. Hemodynamically it is well tolerated due to less ventilation perfusion mismatch $(8,9)$.

Although rare prone position can cause serious complications which can result in long term disability. It includes hypoperfusion hemodynamic changes, ophthalmologic injuries, peripheral nerve compression injuries, compartmental syndrome, pressure ulcers and airway swelling (10). Meralgia paraesthesia, femoral artery thrombosis and avascular necrosis of the hip have also been reported due to excessive pressure over the groin (10-13). Excessive compression pressure over the groin and the anterior superior iliac spine occurs due to the pelvic padding bolsters especially if placed too closely (10). Injury to the lateral cutaneous nerve of the thigh in the prone position causing meralgia paraesthesia is seen in up to $24 \%$ of patients (10). Post-operatively, patients complain of paraesthesia in the thigh with complete resolution of symptoms occurring in most cases within 6 months (10). Risk factors for compression pressure groin injury in the prone position increases with obesity, degenerative spinal disease, inadequate padding and duration of surgery greater than 3.5 hours (10). Our patient developed a right femoral nerve neuropraxia which is extremely rare and not reported previously. It was probably caused by excessive groin pressure from his obesity (BMI of 35), degenerative spine disease and duration of surgery. He however made rapid neuromuscular recovery in the first 2 weeks with mild residual weakness in subsequent follow-ups. This complication can be avoided by careful extra padding of the groin especially in obese patients as well minimising operative time in the prone position.

\section{Conclusions}

Most neurogenic dumbbell tumours can be completely and safely removed by a single stage combined posterior and VATS approach in the prone position avoiding the need for excessive bone removal and complex spinal instrumentation. Meticulous care and extra precautionary measures should be taken to prevent nerve injuries in the groin during prone position.

\section{Acknowledgments}

Funding: None.

\section{Footnote}

Reporting Checklist: The authors have completed the CARE reporting checklist. Available at https://jovs.amegroups. com/article/view/10.21037/jovs-20-141/rc

Conflicts of Interest: Both authors have completed the ICMJE uniform disclosure form (available at https://jovs. amegroups.com/article/view/10.21037/jovs-20-141/coif). TA serves as an unpaid editorial board member of fournal of Visualized Surgery from June 2019 to May 2021. The other author has no conflicts of interest to declare.

Ethical Statement: The authors are accountable for all aspects of the work in ensuring that questions related to the accuracy or integrity of any part of the work are appropriately investigated and resolved. All procedures performed in this study were in accordance with the ethical standards of the institutional and/or national research committee(s) and with the Helsinki Declaration (as revised in 2013). Written informed consent was obtained from the patient for publication of this case report and accompanying images and videos. A copy of the written consent is available for review by the editorial office of this journal.

Open Access Statement: This is an Open Access article distributed in accordance with the Creative Commons Attribution-NonCommercial-NoDerivs 4.0 International License (CC BY-NC-ND 4.0), which permits the noncommercial replication and distribution of the article with 
the strict proviso that no changes or edits are made and the original work is properly cited (including links to both the formal publication through the relevant DOI and the license). See: https://creativecommons.org/licenses/by-nc-nd/4.0/.

\section{References}

1. Topçu S, Alper A, Gülhan E, et al. Neurogenic tumours of the mediastinum: a report of 60 cases. Can Respir J 2000;7:261-5.

2. Akwari OE, Payne WS, Onofrio BM, et al. Dumbbell neurogenic tumors of the mediastinum. Diagnosis and management. Mayo Clin Proc 1978;53:353-8.

3. Payer M, Radovanovic I, Jost G. Resection of thoracic dumbbell neurinomas: single postero-lateral approach or combined posterior and transthoracic approach? J Clin Neurosci 2006;13:690-3.

4. Konno S, Yabuki S, Kinoshita T, et al. Combined laminectomy and thoracoscopic resection of dumbbell-type thoracic cord tumor. Spine (Phila Pa 1976) 200;26:E130-4.

5. Eden K. The dumb-bell tumours of the spine. BJS 1941;28:549-70.

6. Nam KH, Ahn HY, Cho JS, et al. One Stage Posterior Minimal Laminectomy and Video-Assisted Thoracoscopic Surgery (VATS) for Removal of Thoracic Dumbbell

doi: 10.21037/jovs-20-141

Cite this article as: Agasthian T, Khoo JCM. Combined spinal and video-assisted thoracoscopic (VATS) approach to thoracic neurogenic dumbbell tumour in the prone position: a case report. J Vis Surg 2023;9:10.
Tumor. J Korean Neurosurg Soc 2017;60:257-61.

7. Thorat JD, Rajendra T, Thirugnanam A, et al. Singlestage posterior midline approach for dumbbell tumors of the thoracic spine, with intraoperative CT guidance. Surg Neurol Int 2011;2:31.

8. Cuschieri A, Shimi S, Banting S. Endoscopic oesophagectomy through a right thoracoscopic approach. J R Coll Surg Edinb 1992;37:7-11.

9. Agasthian T. Revisiting the prone position in videoassisted thoracoscopic surgery. Asian Cardiovasc Thorac Ann 2010 Aug;18:364-7.

10. DePasse JM, Palumbo MA, Haque M, et al. Complications associated with prone positioning in elective spinal surgery. World J Orthop 2015;6:351-9.

11. Tseng MD, Cappetto L, Majid K, et al. Bilateral femoral artery ischemia detected by multimodality neuromonitoring during posterior scoliosis surgery: a case report. Spine (Phila Pa 1976) 2010;35:E799-E803.

12. Orpen N, Walker G, Fairlie N, et al. Avascular necrosis of the femoral head after surgery for lumbar spinal stenosis. Spine (Phila Pa 1976) 2003;28:E364-E367.

13. Cho KT, Lee HJ. Prone position-related meralgia paresthetica after lumbar spinal surgery: a case report and review of the literature. J Korean Neurosurg Soc 2008;44:392-5. 